\title{
Acute angle-closure glaucoma following botulinum toxin injection for blepharospasm
}

\author{
P Corridan, S Nightingale, N Mashoudi, A C Williams
}

\begin{abstract}
Botulinum toxin inhibits acetylcholine release and therefore could cause mydriasis. We report a case of acute angle-closure glaucoma which occurred shortly after a series of injections of botulinum toxin round the eyelids for blepharospasm.
\end{abstract}

Botulinum toxin as a therapeutic agent was introduced by Scott in $1980^{1}$ for the treatment of squint, and more recently idiopathic blepharospasm has been successfully managed by injection of botulinum toxin into the orbicularis muscle to produce mild paresis. Many hundreds of patients with blepharospasm have been treated without any sight threatening side effects. ${ }^{2}$ We report a case of acute angle-closure glaucoma occurring shortly after botulinum toxin injection for blepharospasm.

\section{Case report}

An 83-year-old woman with a long history of idiopathic blepharospasm was started on botulinum toxin therapy. She had a past history of dry eyes, bilateral macular degeneration, and bilateral levator resections for ptosis. She received a series of injections by a conventional technique.

\section{TECHNIQUE}

$0.05 \mathrm{mg}$ of freeze-dried botulinum toxin haemagglutin complex $(0.008 \mathrm{mg}$ neurotoxin) was reconstituted with $1 \mathrm{ml}$ of sterile saline and then diluted in a further $9 \mathrm{ml}$ of saline. ${ }^{3} \mathrm{~A} 0.5 \mathrm{ml}$ syringe with a $0.36 \mathrm{~mm} \times 12.7 \mathrm{~mm}$ needle was used. Four injections of $0.1 \mathrm{ml}$ or $0.15 \mathrm{ml}$ were given subcutaneously round each eye, two immediately above each eyebrow and two a similar distance below the eye.

Initially she received two $0 \cdot 15 \mathrm{ml}$ injections above each eye and two $0.1 \mathrm{ml}$ injections below each eye, with good relief from blepharospasm and no side effects. Thirteen weeks later blepharospasm had recurred on the right but not on the left. She received two injections of $0.1 \mathrm{ml}$ of toxin above each eye.

Three hours later she developed an ache about her left eye, and within six hours this had become severe and was associated with blurred vision in the left eye, nausea, and vomiting. Despite her severe symptoms she did not seek medical help for her eye condition for a further three days. On examination at the eye casualty department the visual acuity was $6 / 36$ in her right eye and perception of light in her left eye. The conjunctiva and episclera of her left eye were inflamed and the cornea was oedematous.
The intraocular pressures were $60 \mathrm{mmHg}$ in her left eye and $18 \mathrm{mmHg}$ in her right. The left pupil was semidilated and the iris was atrophic. Gonioscopy in the left eye was not possible owing to marked corneal oedema, but the drainage angle in the right eye was very narrow. A diagnosis of left angle-closure glaucoma was made.

She was treated with acetazolamide $500 \mathrm{mg}$ intravenously immediately and also with topical pilocarpine to both eyes and topical prednisolone to the left eye. Two hours later the intraocular pressure had fallen to $36 \mathrm{mmHg}$ in the left eye, and her pain was less severe. Over the next four days the left intraocular pressure remained under control at $28 \mathrm{mmHg}$, though the cornea was oedematous. Bilateral laser iridotomies were performed with a neodymium-yttriumaluminium-garnet laser. Three months later the corneal oedema resolved, but, as the intraocular pressure remained high, trabeculectomy was performed. A month later the left visual acuity was counting fingers, which was approximately the same as the patient had before acute glaucoma developed.

\section{Discussion}

Botulinum neurotoxins act primarily at peripheral cholinergic synapses, where they inhibit the release of acetylcholine. ${ }^{4}$ They are used clinically for their action on the skeletal muscle neuromuscular junction, causing transient muscle paresis. However, botulinum toxins also inhibit acetylcholine release at sympathetic ganglia and at the preganglionic and postganglionic nerve terminals of the parasympathetic nervous system. People systemically poisoned with botulinum toxins characteristically have mid-dilated fixed pupils due to paralysis of the sympathetic and parasympathetic innervation to the iris. ${ }^{5}$ Botulinum toxins could therefore cause pupil dilatation by uptake into the parasympathetic neurones at the level of the ciliary ganglion or at the parasympathetic neuromuscular junctions in the sphincter pupillae of the iris. It has been shown in animal studies that botulinum toxin injected intracamerally $^{6}$ or near the ciliary ganglion ${ }^{7}$ causes mydriasis. We propose that in this patient's eye, which was predisposed to angle closure, acute glaucoma was precipitated by mydriasis caused by botulinum toxin injection around the eye.

Elston ${ }^{3}$ reported a series of 243 patients treated with botulinum toxin for involuntary facial movements, mainly blepharospasm. Some developed diplopia, presumably due to diffusion of the toxin from the orbicularis muscle into the oculomotor muscles. Three patients complained of blurred vision, and it is possible that they had 
ciliary muscle paresis with or without pupil dilatation as a result of botulinum toxin injection.

Scott et al reported a fourfold increase in the incidence of ptosis in patients who, like our patient, had had previous lid surgery. ${ }^{8}$ Diffusion of the toxin into adjacent tissues may be greater in this group.

Angle-closure glaucoma did not occur until the second series of injections in our patient. Similarly, cases of mydriatic glaucoma seen in outpatients have often had their pupils dilated uneventfully on more than one occasion before developing angle closure. ${ }^{9}$ (Smith $\mathrm{RJH}$, personal communication.) The symptoms of angle closure in our patient developed only six hours after the injection. Usually the toxin has its maximum effect on the levator on the third postinjection day, ${ }^{10}$ when this diagnosis of glaucoma was confirmed. Moreover, the toxin appears to exert an effect more rapidly on the pupils than on skeletal muscle, as in botulism, where blurred vision normally precedes skeletal muscle paralysis. $^{5}$

This is the first reported case of acute angleclosure glaucoma following a therapeutic injection of botulinum toxin. We recommend gonioscopy to assess the potential for angle closure in all adults prior to treatment with botulinum toxin for blepharospasm, and particularly in those who have had previous eyelid surgery. Patients should be warned of this side effect and advised to report symptoms of early acute glaucoma immediately. Those who are shown to be at risk could have prophylactic YAG laser iridotomies.

We thank Miss E M Eagling for permission to report this case and Mr M J Roper-Hall for his help and advice.

1 Scott AB. Botulinum toxin injection into extraocular muscles as an alternative to strabismus surgery. Ophthalmology 1980 87: 1044-7.

2 Dutton JJ, Buckley EG. Long term results and complications of botulinum A toxin in the treatment of blepharospasm. Ophthalmology 1988; 95: 1529-34.

3 Elston JS. Botulinum toxin therapy for involuntary facial

movement. Eye 1988; 2: 12-5.
4 Melling J, Hambleton P, Shone CC. Clostridium botulinum toxins: nature and preparation for clinical use. Eye 1988; 2 16-23.

5 Walsh FB, Hoyt WF. Clinical neuro-ophthalmology. Baltimore: Williams and Wilkins, 1969; 2: 1476-9.

6 Ambache $\mathrm{N}$. The periphenal action of $\mathrm{Cl}$ botulinum toxin. $\mathcal{F}$ Physiol (Lond) 1949; 108: 127-41.

7 Kupfer C. Selective block of synaptic transmission in a ciliary ganglion by type A botulinus toxin in rabbits. Proc Soc Exp Biol Med 1958;99: 474-6.

8 Scott AB, Kennedy RA, Stubbs HA. Botulinum A toxin injection as a treatment for blepharospasm. Arch Ophthalmol 1985; 103: 347-50.

9 Lowe RF. Primary angle-closure glaucoma; a review of provocative tests. Brf Ophthalmol 1967; 51: 727-32.

10 Adams GGW, Kirkness CM, Lee JP. Botulinum toxin A induced protective ptosis. Eye 1987; 1: 603-8. 